\title{
Morphologic Features of Endometriosis in Various Types of Cytologic Specimens
}

Güliz A. Barkan, M.D., ${ }^{1 *}$ Bernard Naylor, M.D., ${ }^{2}$ Paolo Gattuso, M.D., ${ }^{3}$

Sevgi Küllü, M.D., ${ }^{4}$ Kristine Galan, M.D., ${ }^{3}$ and Eva M. Wojcik, M.D. ${ }^{1}$

Endometriosis is defined as the presence of endometrial tissue outside the uterine cavity. This study evaluates the cytomorphologic features of endometriosis in various cytologic specimen types [fine-needle aspiration (FNA), effusion cytology (EF), touch imprint (ToP), and cervical smear (PAP)], and assesses the key elements helpful in recognizing this lesion. A total of 18 cases ( $8 \mathrm{FNA}, 4 \mathrm{EF}, 5 \mathrm{ToP}$, and $1 \mathrm{PAP}$ ) of cytologically diagnosed and histologically/clinically confirmed endometriosis diagnosed between 1988 and 2006 comprises the material for this study. The morphologic features evaluated of the three components included: cellularity, presence of sheets of glandular cells, three-dimensional (3D) glandular clusters, tubular structures, single cells, syncytial groups of stromal cells, stromal cells entrapped within basement membrane (BM)-like material, cytologic atypia, presence of mitotic figures, and hemosiderin-laden histiocytes. Endometrial glands, stroma, and hemosiderin-laden histiocytes were all identified in $14 / 18$ (77.8\%) cases. FNA specimens were more cellular than that of both EF and ToP specimens. Tubular structures, 3D glandular clusters, stromal cells entrapped in BM and syncytial stromal groups were more common in FNAs, and ToPs compared with the EFs. The ratio of the endometrial glandular and stromal cells was similar in all specimen types. Atypia and mitotic figures were rarely encountered. Diagnosis of endometriosis could be made independently on either smears/ThinPrep ${ }^{T M}$ slides or on cell blocks in all cases where these preparations were available. On follow up, none of the patients developed malignancy. Endometriosis can be reliably and safely diagnosed in various cytologic mate-

${ }^{1}$ Department of Pathology, Loyola University Medical Center, Maywood, Illinois

${ }^{2}$ Department of Pathology, University of Michigan, Ann Arbor, Michigan

${ }^{3}$ Department of Pathology, Rush University Medical Center, Chicago, Illinois

${ }^{4}$ Department of Pathology, Marmara Pathology Laboratory, Istanbul, Turkey

*Correspondence to: Güliz A. Barkan M.D., Associate Professor of Pathology, Loyola University Medical Center, Department of Pathology, Bldg 110, 2130 South First Ave, Maywood, IL 60153. E-mail: gbarkan@lumc.edu

Received 18 February 2011; Accepted 1 January 2013

DOI: $10.1002 /$ dc. 22979

Published online 20 March 2013 in Wiley Online Library (wileyonlinelibrary.com). rials. Cytologic atypia is uncommon. Components of endometriosis could show minor morphologic alterations in different specimen types. Diagn. Cytopathol. 2013;41:936-942. () 2013 Wiley Periodicals, Inc.

Key Words: endometriosis; cytology; FNA; effusion

Endometriosis is a relatively common disease, defined as the presence of functional endometrial tissue outside the uterus. ${ }^{1}$ Ectopic endometrial tissue is identified as endometrial glands and stromal tissue usually accompanied by hemosiderin-laden histiocytes. Most of the time, histologic identification of two of the three components could be sufficient for the diagnosis. ${ }^{1}$

Endometriosis primarily affects women of reproductive age and has symptoms varying from occult to more specific complaints. The most common site for endometriosis is the ovary, ${ }^{2}$ although there has been reports of endometriosis in the uterine ligaments, ${ }^{3}$ rectovaginal septum, ${ }^{4}$ fallopian tubes, ${ }^{3}$ rectosigmoid colon, ureter, ${ }^{5}$ bladder, ${ }^{6}$ umbilicus, ${ }^{7,8}$ inguinal, ${ }^{8}$ and perianal regions. ${ }^{9}$ Endometriosis could also be scar-related, occurring after operations on the uterus or fallopian tubes particularly in the lower abdominal wall or episiotomy scars. ${ }^{8,10-12}$ Cutaneous, scar-related endometriosis presents as a mass/nodule appearing weeks to years following surgery and shows catamenial increase in size and tenderness with occasional bleeding from the lesion.

Endometriosis can be managed by either medical or surgical treatment. As previously reported, endometriosis can be accurately diagnosed by aspiration cytology. ${ }^{4,13-28}$ Endometriosis has been reported in a variety of specimen types: fine-needle aspiration (FNA), ${ }^{4,13,16,18,19,26,29}$ effusion samples, ${ }^{28,30}$ and cervical smears. ${ }^{20,22,23,25}$ According to the different body sites and specimen types, the differential diagnosis may vary, but in most cases, it includes benign hemorrhagic cyst, follicular cyst, hematoma, endosalpingiosis, and adenocarcinoma, especially in aspirates of intraabdominal, pelvic sites, and effusion fluid 
samples from hemothorax and hemoperitoneum. To diagnose endometriosis by cytology accurately, a good understanding of cytomorphology in various specimens and preparations is necessary. To our knowledge, a comparative study of the cytologic features of endometriosis in different cytology specimen types has not been reported. The aim of this study is to investigate, compare and define the similarities and differences between the cytomorphological features of endometriosis seen in different cytologic specimen types [FNA, effusion cytology (EF), touch imprint (ToP), and cervical smear (PAP)], and to assess the key cytomorphological features characteristic for this entity.

\section{Methods}

The electronic files of the Loyola University Medical Center, Maywood, IL; Rush University Medical Center, Chicago, IL; and Marmara Pathology Center, Istanbul, Turkey were searched for cases of endometriosis in cytopathology and surgical pathology material diagnosed between January 1988 and February 2006. A total of 28 cases of cytologically diagnosed endometriosis cases were identified. Of these cases, three did not have histological/ clinical confirmation and nine cases were not available for review; these cases were excluded from evaluation. Of the remaining 18 cases, all were histologically (12) or clinically (6) confirmed. The patients were followed up for a mean of 8.4 years (range 5-13 years), and none of them developed a neoplasm in this period. The study cases are composed of four EF [peritoneal (2) cul-de-sac (1), and pelvic (1)], eight FNA [ovary (4), pelvic (2), abdominal wall (2)], five ToP [abdominal wall (3) and ovary (2)] and 1 PAP.

\section{Specimen Preparation}

Effusion specimens. All four cases were received in Cytolyt (Hologic, Bedford, MA) from which a ThinPrep ${ }^{\text {TM }}$ (Hologic, Bedford, MA) and a cell block were prepared in all four cases.

FNA specimens. The FNA was performed by a pathologist or a clinician either transcutaneously (2), or by ultrasound-guidance (6). One to four passes were performed and an immediate assessment was performed in cases where aspiration was performed by a pathologist. In six cases, a ThinPrep ${ }^{\mathrm{TM}}$ and in seven cases a cell block was prepared. In addition, ethanol-fixed, Papanicolaou stained and air-dried, Diff-Quik (Baxter Scientific Products, McGraw Park, IL) stained smears were prepared.

Cervical smears. The specimen was received in Cytolyt (Hologic, Bedford, MA) and a ThinPrep ${ }^{\text {тм }}$ was prepared.
Table I. Cytomorphologic Features Reviewed

\begin{tabular}{|c|c|c|}
\hline Glandular cells & Stromal cells & $\begin{array}{c}\text { Pigment-laden } \\
\text { macrophages }\end{array}$ \\
\hline Cellularity & Cellularity & $\begin{array}{l}\text { Presence/ } \\
\text { Absence }\end{array}$ \\
\hline Single cells & Single cells & \\
\hline Sheets/syncytial clusters & Sheets/syncytial clusters & \\
\hline $\begin{array}{l}\text { Three-dimensional } \\
\text { groups }\end{array}$ & Three-dimensional groups & \\
\hline Tubular formation & Nuclear palisading & \\
\hline Nuclear palisading & $\begin{array}{l}\text { Cells entrapped in BM-like } \\
\text { material }\end{array}$ & \\
\hline $\begin{array}{l}\text { Cells entrapped in } \\
\text { BM-like material }\end{array}$ & $\begin{array}{l}\text { Atypia (hyperchromasia, } \\
\text { nuclear membrane } \\
\text { irregularity, and high } \\
\text { nuclear cytoplasmic ratio) }\end{array}$ & \\
\hline $\begin{array}{l}\text { Atypia (hyperchromasia, } \\
\text { nuclear membrane } \\
\text { irregularity, high } \\
\text { nuclear cytoplasmic } \\
\text { ratio) }\end{array}$ & & \\
\hline
\end{tabular}

Touch imprints. ToPs were made, as an intraoperative diagnosis from the surgical specimens and were either stained with Diff-Quik or Hematoxylin and Eosin.

Evaluation of cytomorphologic features. The morphological features that were evaluated and tabulated are presented in Table I.

\section{Results}

The patients ages ranged from 20 to 65 years (mean 37 years) and the size of the mass ranged from 1 to $12 \mathrm{~cm}$ (mean $4.2 \mathrm{~cm}$ ). The demographic data of the patients and the follow up information are shown in Table II. The criteria for the diagnosis of endometriosis was identifying the presence of either endometrial glands or stroma or both, with or without the presence of hemosiderin-laden macrophages. The FNA and ToP samples were more cellular than those of the EF samples. All three (glandular, stromal, and histiocytic) components were identified in $4 / 4(100 \%)$ of the EF, $6 / 8(75 \%)$ of FNA, and $4 / 5(80 \%)$ of ToP. The cell block sections of these cases showed all three components in $4 / 4(100 \%)$ of the EF, $4 / 8(50 \%)$ of FNA specimens. There were no cell blocks on one FNA case, the PAP and the ToP cases. The diagnosis of endometriosis could be made independently on either smears/ ThinPrep $^{\mathrm{TM}}$ slides or on cell blocks in all cases where both preparations were available. On one FNA case, all components were identified on the smears but only the histiocytic component was seen on the cell block; and on a second FNA case only histiocytes were seen on the smear and both glandular component and histiocytes were identified on the cell block. One FNA case only had abundant hemosiderin-laden histiocytes on both ThinPrep and cell block sections. On this case, the diagnosis of endometriosis was suggested based on the patients' history of extensive pelvic endometriosis. The PAP showed 
BARKAN ET AL.

Table II. Demographic data and follow up of the cases

\begin{tabular}{llllll}
\hline No & Age & Type & \multicolumn{1}{c}{ Site } & \multicolumn{1}{c}{ Size } & Follow up \\
\hline Case 1 & 29 & EF & peritoneal & n/a & surgical \\
Case 2 & 42 & EF & Cul-de-sac & n/a & surgical \\
Case 3 & 42 & EF & pelvic & n/a & surgical \\
Case 4 & 45 & EF & peritoneal & n/a & clinical \\
Case 5 & 37 & FNA & pelvic & $12 \mathrm{~cm}$ & clinical \\
Case 6 & 45 & FNA & pelvic & $4.2 \mathrm{~cm}$ & surgical \\
Case 7 & 25 & FNA & ovary cyst & $1 \mathrm{~cm}$ & surgical \\
Case 8 & 38 & FNA & ovary cyst & $3.1 \mathrm{~cm}$ & surgical \\
Case 9 & 47 & FNA & ovary cyst & $3 \mathrm{~cm}$ & clinical \\
Case 10 & 27 & FNA & abdominal wall & $4.6 \mathrm{~cm}$ & clinical \\
Case 11 & 41 & FNA & ovary cyst & $2 \mathrm{~cm}$ & surgical \\
Case 12 & 40 & FNA & abdominal wall & $6 \mathrm{~cm}$ & clinical \\
Case 13 & 65 & PAP & cervical smear & n/a & surgical \\
Case 14 & 25 & ToP & abdominal wall & $2 \mathrm{~cm}$ & surgical \\
Case 15 & 29 & ToP & abdominal wall & $2 \mathrm{~cm}$ & surgical \\
Case 16 & 28 & ToP & abdominal wall & $2.5 \mathrm{~cm}$ & surgical \\
Case 17 & 20 & ToP & ovary & $5 \mathrm{~cm}$ & surgical \\
Case 18 & 44 & ToP & ovary & $7 \mathrm{~cm}$ & surgical
\end{tabular}

EF, Effusion; FNA, Fine-needle aspiration; PAP, cervical smear; ToP, Touch imprint; n/a, not applicable.

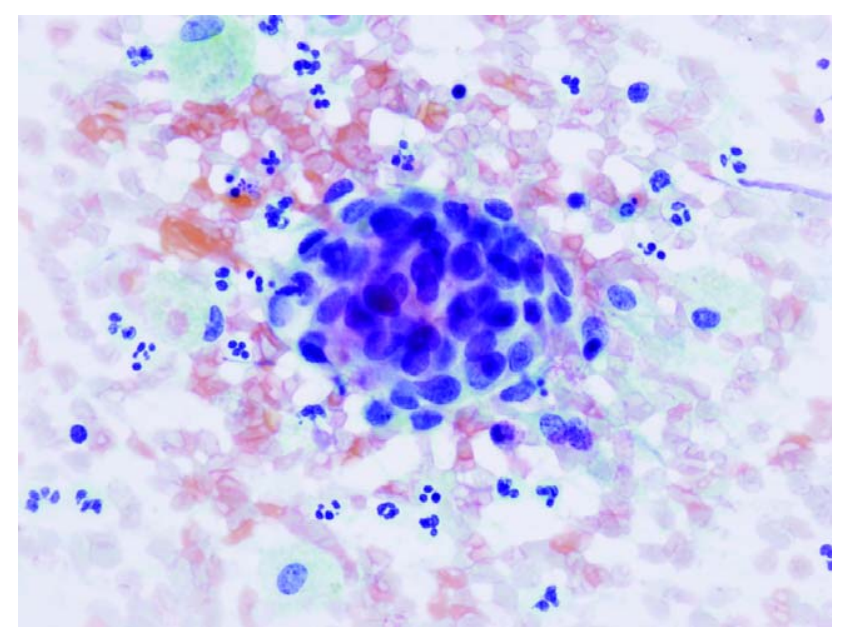

Fig. 1. Glandular cells forming a tight three-dimensional cluster. The endometrial glandular cells have indistinct cell borders, scant cytoplasm, small round to oval nuclei, and inconspicuous nucleoli. In the background, there are rare histiocytes. (FNA, conventional smear, Papanicolaou stain, $600 \times)$. [Color figure can be viewed in the online issue, which is available at wileyonlinelibrary.com.]

the glandular component and stromal components but hemosiderin-laden histiocytes were not identified. One ToP case showed glandular and histiocytic components only. There was no significant difference between the amount of glandular and stromal components in EF, FNA, PAP, and ToP.

The glandular component consisted of three-dimensional, tight clusters of cells with small round nuclei akin to that seen in the PAP (Fig. 1) and occasional sheets of columnar cells in a honeycomb arrangement (Fig. 2) composed with ovoid nuclei, mostly inconspicuous nucleoli and scanty cytoplasm. Some groups showed nuclear pali-

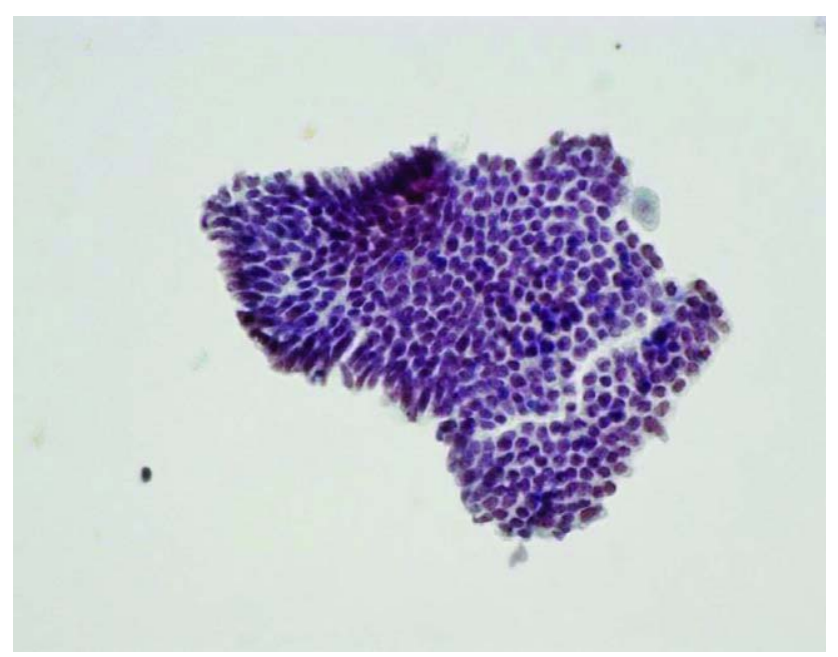

Fig. 2. Endometrial cells forming a sheet with honeycomb arrangement. The nuclei are small and round, devoid of cytologic atypia. There is minimal nuclear overlap and nuclear palisading at the edge of the sheet. (Thin Prep ${ }^{\mathrm{TM}}$, Papanicolaou stain, $400 \times$ ). [Color figure can be viewed in the online issue, which is available at wileyonlinelibrary.com.]

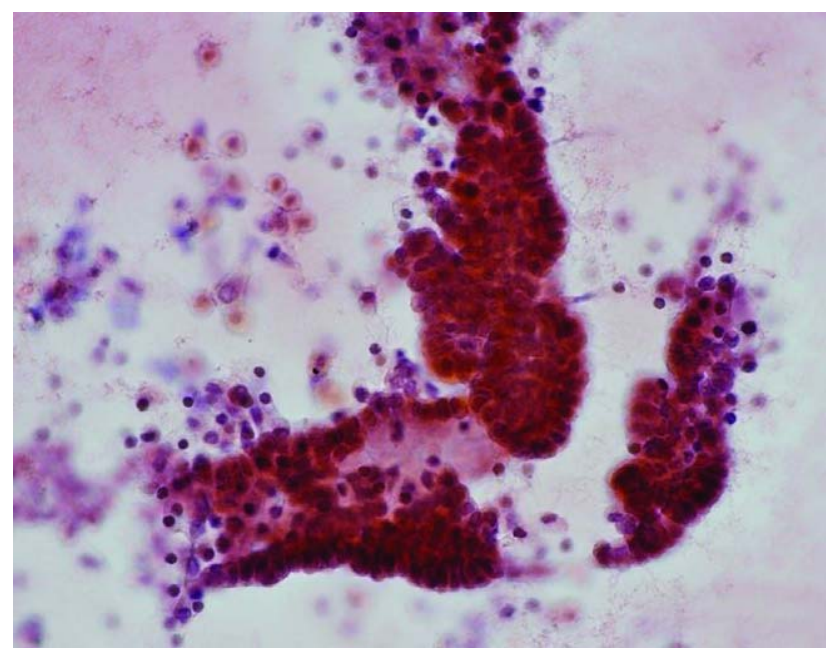

Fig. 3. Groups of endometrial glandular cells forming a tubular structure (in the bottom) and showing nuclear palisading at the edge of the groups. (Cytospin, Papanicolaou stain, $400 \times$ ). [Color figure can be viewed in the online issue, which is available at wileyonline library.com.]

sading and occasionally a tubular configuration (Fig. 3) was identified. The most common glandular component consisted of three-dimensional groups (14/18; 77.8\%). Small sheets of columnar cells were identified only in some FNA and ToP samples $(6 / 18 ; 33.3 \%)$. Atypical cells were observed in the form of mild nuclear enlargement only in $3 / 18 ; 16.7 \%$ (two FNAs and one PAP). Rare mitotic figures were observed in only $2 / 18$ cases $(11.1 \%$; one FNA and one PAP) case. None of the mitotic figures were of atypical nature. Nuclear palisading in the glandular groups were seen in 6/18; 33.3\% (four FNA, one ToP, 


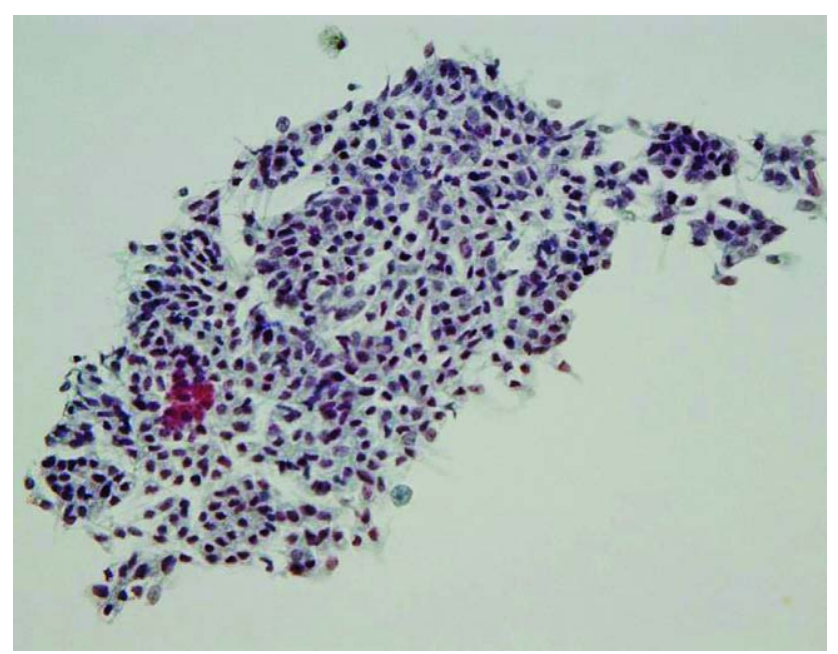

Fig. 4. Loosely cohesive groups of stromal cells. The cells have a scant cytoplasm and round to oval nuclei. (Thin Prep ${ }^{\mathrm{TM}}$, Papanicolaou stain, $400 \times$ ). [Color figure can be viewed in the online issue, which is available at wileyonlinelibrary.com.]

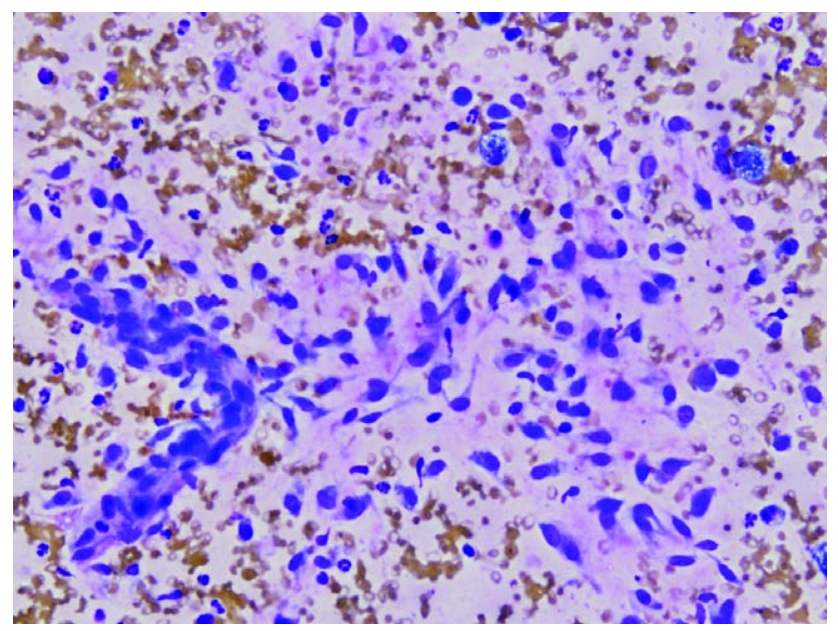

Fig. 5. Stromal cells mostly seen singly and in a small loosely cohesive group. The cells are spindled with scant cytoplasm and round to oval nuclei. Also, note the foamy histiocytes in the background. (Thin Prep ${ }^{\mathrm{TM}}$, Diff Quik stain, 600×). [Color figure can be viewed in the online issue, which is available at wileyonlinelibrary.com.]

and one EF) cases. Tubular groups were identified in 4/18; 22.2\% (three FNA and one ToP) cases.

The stromal component consisted of syncytial groups of oval to spindled cells with indiscrete cytoplasmic borders (Fig. 4). Sometimes, the stromal component was seen as single cells, (Fig. 5) and sometimes as plumpspindled cells attached to basement membrane (BM)-like material, which stained metachromatic with Diff-Quik stain. Fragments of BM with attached stromal cells were identified in 9/18; 50\% (five FNA, four ToP) cases. Decidualized stromal cells as reported before, ${ }^{15}$ were observed in 3/18; $16.7 \%$ (two FNA and one ToP) cases.

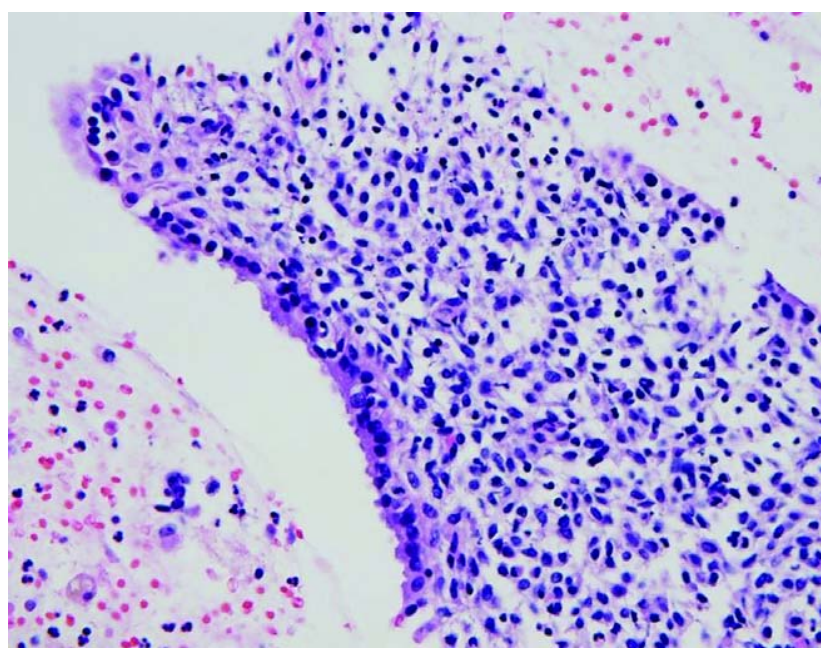

Fig. 6. Cell block section showing a lining of glandular cells overlying the loosely cohesive stromal cells. Away from the tissue fragment are foamy histiocytes, some of which are hemosiderin laden. (FNA, cell block, H\&E stain, 200×). [Color figure can be viewed in the online issue, which is available at wileyonlinelibrary.com.]

The stromal component was mostly observed in syncytial clusters $16 / 18 ; 88.9 \%$. Single stromal cells were seen in 9/18; 50\% (one EF, two FNA, one PAP, and five ToP) cases. As described earlier, most cell block sections contained both glandular and stromal cells as well as hemosiderin-laden histiocytes (Fig. 6)

Foamy histiocytes, which were mostly pigment-laden, were seen in the majority of the cases. The pigments found in the histiocytes are believed to be hemofuchsin, and hemosiderin. ${ }^{1}$ The histiocytic component was identified in 17/18 cases, $94.4 \%$ (one PAP did not have a histiocytic component). The histiocytic component was mostly slight to moderately cellular (16/18 cases, $88.9 \%)$. The two cases that had a high histiocyte count had an increased amount of intracellular and extracellular pigment, but did not show glandular or stromal components. Of these cases, one was a FNA of a pelvic mass and the other was a ToP from the ovary. The FNA case was from a patient with an extensive pelvic endometriosis and a $12 \mathrm{~cm}$ mass. In the cases that had histiocytes, these cells were found singly in all 17/17 (100\%). In about half of the cases, histiocytes were also found in small groups $(9 / 17 ; 52.9 \%)$. Extracellular pigment was identified in $9 / 17 ; 52.9 \%$ (one EF, six FNA, and two ToP) cases and intracellular pigment (within the histiocytes) was identified in 14/15; $82.3 \%$ (four EF, seven FNA, and three ToP) cases. Cytomorphologic features of endometriosis in different specimen types (FNA, EF, and ToP) are summarized in Table III. In one FNA case, immunohistochemical study was performed on the cell block section, which revealed a strong positivity for CD 10 in the stromal cells. 
Table III. Summary of cytomorphologic features of endometriosis in different cytologic specimen types

\begin{tabular}{|c|c|c|c|}
\hline \multirow{2}{*}{$\begin{array}{l}\text { Cellularity } \\
\text { Glandular cells }\end{array}$} & $\begin{array}{c}\text { Effusion } \\
\text { Low-cellularity }\end{array}$ & $\begin{array}{c}\text { FNA } \\
\text { Moderate-cellularity }\end{array}$ & $\begin{array}{c}\text { ToP } \\
\text { Low-moderate cellularity }\end{array}$ \\
\hline & $\begin{array}{l}\text { 3D clusters, tubular structures, and rare } \\
\text { single glandular cells }\end{array}$ & $\begin{array}{l}\text { 3D clusters, sheets, tubular structures, and } \\
\text { single glandular cells with round to oval } \\
\text { nucleus; occasional peripheral nuclear } \\
\text { palisading }\end{array}$ & $\begin{array}{l}\text { 3D clusters, rare sheets, tubular } \\
\text { structures, and single glandular cells }\end{array}$ \\
\hline \multirow{4}{*}{ Stromal cells } & No atypia or mitotic figures & $\begin{array}{l}\text { Two cases with cellular atypia (mild } \\
\text { nuclear enlargement and nuclear } \\
\text { overlapping) and rare mitotic figures }\end{array}$ & No cellular atypia or mitotic figures \\
\hline & Glandular cells $>$ stromal cells & Glandular cells $=$ stromal cells & Glandular cells $=$ stromal cells \\
\hline & $\begin{array}{l}\text { Rare syncytial clusters of loosely arranged } \\
\text { oval to spindled cells with small nuclei, } \\
\text { and scant cytoplasm }\end{array}$ & $\begin{array}{l}\text { Fragments of metachromatic basement- } \\
\text { membrane type material with attached } \\
\text { stromal cells, rare decidualized cells } \\
\text { with polygonal, and dense cytoplasm }\end{array}$ & $\begin{array}{l}\text { Syncytial clusters of loosely arranged } \\
\text { cells and single cells, oval to } \\
\text { spindled with scant cytoplasm and } \\
\text { rare decidualization }\end{array}$ \\
\hline & No atypia or mitotic figures & No atypia or mitotic figures & No atypia or mitotic figures \\
\hline
\end{tabular}

Table IV. Morphological features of endometriosis on FNA and Effusion specimens

\begin{tabular}{|c|c|c|c|c|}
\hline Author & Year & No. cases & Site & Procedure \\
\hline Fulciniti et al. ${ }^{16}$ & 2005 & 10 cases & Abdominal/pelvic & FNA \\
\hline Slade et al. ${ }^{30}$ & 2004 & 1 case & Peritoneal & Gutter washing \\
\hline Simsir et al. ${ }^{29}$ & 2001 & 3 cases & Abdominal scar & FNA \\
\hline Gupta et al. ${ }^{19}$ & 2000 & 1 case & Abdominal scar & FNA \\
\hline Ashfaq et al. ${ }^{13}$ & 1994 & 3 cases & $\begin{array}{l}\text { Inguinal } \\
\text { Abdominal } \\
\text { Paraumbilical }\end{array}$ & FNA \\
\hline Tabbara et al. ${ }^{26}$ & 1991 & 3 cases & $\begin{array}{l}\text { Vaginal cuff } \\
\text { Paraumbilical } \\
\text { Suprapubic }\end{array}$ & FNA \\
\hline Leiman et al. ${ }^{4}$ & 1986 & $2 \mathrm{ca}$ & Rectovaginal septum & FNA \\
\hline Griffin et al. ${ }^{18}$ & 1985 & 2 cases & $\begin{array}{l}\text { Suprapubic } \\
\text { Thigh }\end{array}$ & FNA \\
\hline Zaatari et al. ${ }^{28}$ & 1983 & 2 cases & Pleural & Thoracentesis \\
\hline
\end{tabular}

\section{Discussion}

Endometriosis is a common disease that can be accurately diagnosed in various cytologic specimens. Prior reports on endometriosis on FNA and effusion specimens are summarized in Table IV. Although endometriosis is defined as the presence of endometrial glandular, stromal cells and potentially hemosiderin-laden histiocytes, the presence of two components could be sufficient to render this diagnosis. Rare cases of endometriosis may be composed of stromal elements only, also known as 'stromal endometriosis'. 31 Hemorrhage may occur within the stroma and the glandular lumens of the endometriotic foci. In addition, a secondary inflammatory response consisting predominantly of a diffuse infiltration of histiocytes could be observed. Over time, the histiocytes convert the extravasated red blood cells into glycolipid and hemosiderin, becoming the pseudoxanthoma cells that can replace the endometriotic stroma. ${ }^{32,33}$ This study contains three cases with only two components and one case with only histiocytes. The case with only histiocytes on the smears was from a pelvic mass lesion of $12 \mathrm{~cm}$, which was confirmed histologically and clinically to be endometriosis. As described, when the size of the mass increases, and with time, one is more likely to find only histiocytes in an endometriotic mass. ${ }^{32,33}$ In general, definitive diagnosis of endometriosis in cases, where only histiocytes are identified is not recommended on cytology specimens. Rather a description of the findings with recommended correlation with the clinical findings presents a better option. Of the three cases with two components, only one was a ToP of multiple cysts in the pelvis/ovary showing only stromal and histiocytic component. This case could be histologically classified as a "stromal endometriosis." The second case was a PAP showing stromal and glandular components only. The third case was an FNA of an ovarian cyst with abundant histiocytes and a rare glandular component.

Scar-related endometriosis occurring after operations on the uterus or fallopian tubes is seen most commonly in the lower abdominal wall or in episiotomy scars. ${ }^{8,10-12}$ Spontaneous cutaneous endometriosis typically involves the umbilicus ${ }^{8,9}$ and less commonly the inguinal ${ }^{8}$ and perianal regions. ${ }^{9}$ The most common symptom is a cutaneous mass/nodule appearing weeks to years after surgery. Catamenial increase in size and tenderness with occasional bleeding from the lesion is suggestive of the diagnosis. In endometriotic cysts of the ovary, the stromal and epithelial lining could become attenuated and the recognition is based on a small rim of stromal cells and pseudoxanthoma cells. Occasionally, the epithelial cells lining endometriotic cysts are large, cuboidal with abundant eosinophilic cytoplasm and atypical nuclear features. $^{32,34,35}$ In this series, only three cases showed atypical cells (two FNA and one PAP). The presence of atypia in endometriosis is well documented ${ }^{13,23,25,26,30}$ and does not have a prognostic implication, unless the atypia is severe warranting a diagnosis of adenocarcinoma arising in endometriosis. From the three cases with atypia, two of them (one FNA and one PAP) also had rare mitotic figures and mild nuclear enlargement, similar to that of other studies. ${ }^{26,30}$ 
Certain morphological trends have been observed between the different types of specimens. The tubular groups were more common on FNAs. Glandular groups tended to round up and be interpreted as three-dimensional groups on ThinPrep specimens prepared from EF samples. Nuclear palisading described in several articles ${ }^{26}$ as well as fragments of BM with attached stromal cells also seemed to be more of a feature of FNA and ToP compared with other specimen types. The EF samples were less cellular and a history of abdominal/peritoneal endometriosis facilitated the diagnosis.

The diagnosis of endometriosis could be made independently on either smears or on cell-blocks. However, in cases of low cellularity the use of cell-block could aid in diagnosis.

It is also important to keep potential pitfalls in mind, which include but are not limited to endosalpingiosis, adenocarcinoma, metastatic neoplasms, granulomas, and low grade endometrial stromal sarcomas. The presence of ciliated tubal epithelium would suggest the diagnosis of endosalpingiosis. Granulomas lack glandular epithelium and intermixed epithelioid histiocytes and chronic inflammatory cells exhibit the characteristic features. In cases where glandular components predominate and atypia is significant, the diagnosis of adenocarcinoma is an imperative consideration. In general, unless there is marked hyperchromasia, pleomorphism, prominent, macronucleoli, and marked nuclear membrane irregularity a diagnosis of adenocarcinoma is not warranted. Careful attention has to be paid to the presence of stromal cells and hemosiderin-laden histiocytes and, in most cases, the uniform architecture of glandular components and, most importantly, the lack of single epithelial cells all of which favor endometriosis over adenocarcinoma. Lastly, endometriosis has to be differentiated from stromal sarcomas. Again, lack of atypia in the stromal cells and the absence of the other components could eliminate this malignancy from the differential diagnosis.

In the days of constantly improving imaging techniques, smaller and unexpected lesions are incidentally discovered. Considering the high prevalence of endometriosis, there is higher probability of detecting those lesions even before they become clinically apparent. With an increasing popularity of EUS-guided FNA the probability of endometriosis being aspirated is high. ${ }^{36-38}$ In this context, familiarity with cytologic features of endometriosis is particularly important in preventing a false positive diagnosis of malignancy and its consequences.

Knowledge of features of endometriosis also becomes important in the intraoperative diagnosis using ToP especially in distinguishing endometriosis from adenocarcinoma. A clinical suspicion for endometriosis, and knowing its various cytologic features could aid in the diagnosis of these lesions, relieving the surgeons and patients from unnecessary surgical procedures.

In summary, we have presented a series of cytologically diagnosed cases of endometriosis, systematically described the diagnostic features, and showed that the cytologic diagnosis of endometriosis can be made or at least suggested in a right clinical setting. Considering the frequency of this disease and ever increasing imaging techniques, it is pertinent to be familiar with the cytologic features in different specimen types.

\section{References}

1. Blaustein A, Kurman RJ. Blaustein's pathology of the female genital tract. New York: Springer; 2002. xv, 1391 p.

2. Rubenchik I, Auger M, Casper RF. Fine-needle aspiration cytology of ovarian cysts in in vitro fertilization patients: A study of 125 cases. Diagn Cytopathol 1996;15:341-344.

3. Zanetta G, Lissoni A, Dalla Valle C, Trio D, Pittelli M, Rangoni G. Ultrasound-guided aspiration of endometriomas: Possible applications and limitations. Fertil Steril 1995;64:709-713.

4. Leiman G, Markowitz S, Veiga-Ferreira MM, Margolius KA. Endometriosis of the rectovaginal septum. Diagnosis by fine needle aspiration cytology. Acta Cytol 1986;30:313-316.

5. Akin MR, Ho CS, Nguyen GK. Cystic endometriosis and related neoplasms arising from extragonadal endometriosis diagnosed by transvaginal fine needle aspiration biopsy. Acta Cytol 1999;43:536538.

6. Bergqvist A. Extragenital endometriosis. A review. Eur J Surg 1992;158:7-12.

7. Michowitz M, Baratz M, Stavorovsky M. Endometriosis of the umbilicus. Dermatologica 1983;167:326-330.

8. Steck WD, Helwig EB. Cutaneous endometriosis. Clin Obstet Gynecol 1966;9:373-383.

9. Minvielle L, De La Cruz JV. Endometriosis of the anal canal: Presentation of a case. Dis Colon Rectum 1968;11:32-35.

10. Chatterjee SK. Scar endometriosis: A clinicopathologic study of 17 cases. Obstet Gynecol 1980;56:81-84.

11. Lauchlan SC. Two types of muellerian epithelium in an abdominal scar. Am J Obstet Gynecol 1965;93:89-90.

12. Wolf GC, Singh KB. Cesarean scar endometriosis: a review. Obstet Gynecol Surv 1989;44:89-95.

13. Ashfaq R, Molberg KH, Vuitch F. Cutaneous endometriosis as a diagnostic pitfall of fine needle aspiration biopsy. A report of three cases. Acta Cytol 1994;38:577-581.

14. Baram A, Bagan P, Danel C, Badia A, Riquet M. [Pleural endometriosis: an unusual presentation]. Rev Mal Respir 2005;22:677-680.

15. Berardo MD, Valente PT, Powers CN. Cytodiagnosis and comparison of nondecidualized and decidualized endometriosis of the abdominal wall. A report of two cases. Acta Cytol 1992;36:957-962.

16. Fulciniti F, Caleo A, Lepore M, Fortunato A, Vetrani A, Palombini L. Fine needle cytology of endometriosis: Experience with 10 cases. Acta Cytol 2005;49:495-499.

17. Goldberg G, Learmonth G, Bloch B, Levin W. Role of cul-de-sac aspiration cytology in the management and follow-up of patients with ovarian carcinoma. A preliminary report. J Reprod Med 1985;30:867-870.

18. Griffin JB, Betsill WL, Jr. Subcutaneous endometriosis diagnosed by fine needle aspiration cytology. Acta Cytol 1985;29:584-588.

19. Gupta RK, Green C, Wood KP. Fine needle aspiration cytodiagnosis of endometriosis in an abdominal scar after caesarean section. Cytopathology 2000;11:67-68. 
20. Hanau CA, Begley N, Bibbo M. Cervical endometriosis: A potential pitfall in the evaluation of glandular cells in cervical smears. Diagn Cytopathol 1997;16:274-280.

21. Kumar PV, Esfahani FN. Cytopathology of peritoneal endometriosis caused by ruptured ovarian cysts. Acta Cytol 1988;32:523-526.

22. Lundeen SJ, Horwitz CA, Larson CJ, Stanley MW. Abnormal cervicovaginal smears due to endometriosis: A continuing problem. Diagn Cytopathol 2002;26:35-40.

23. Mulvany NJ, Surtees V. Cervical/vaginal endometriosis with atypia: A cytohistopathologic study. Diagn Cytopathol 1999;21:188-193.

24. Saint-Pol P, Leroy JL, Hermand E, Puech J. [Cytology of peritoneal fluid in the diagnosis of pelvic endometriosis]. J Gynecol Obstet Biol Reprod (Paris) 1984;13:781-784.

25. Szyfelbein WM, Baker PM, Bell DA. Superficial endometriosis of the cervix: A source of abnormal glandular cells on cervicovaginal smears. Diagn Cytopathol 2004;30:88-91.

26. Tabbara SO, Covell JL, Abbitt PL. Diagnosis of endometriosis by fine-needle aspiration cytology. Diagn Cytopathol 1991;7:606-610.

27. Villalta J, Custardoy AL, Carrasquer JA, Pujala M, Gambo P. [Endometriosis in a laparotomic scar after cesarean section: Report of two cases]. Cir Esp 2006;79:313-315.

28. Zaatari GS, Gupta PK, Bhagavan BS, Jarboe BR. Cytopathology of pleural endometriosis. Acta Cytol 1982;26:227-232.

29. Simsir A, Thorner K, Waisman J, Cangiarella J. Endometriosis in abdominal scars: A report of three cases diagnosed by fine-needle aspiration biopsy. Am Surg 2001;67:984-986.
30. Slade AJ, Dieterich M, Sturgis CD. Eosinophilic metaplastic atypia in exfoliated cells of ovarian endometriosis: A potential cytodiagnostic pitfall in peritoneal fluids. Diagn Cytopathol 2004;31:123125.

31. Clement PB, Young RH. Two previously unemphasized features of endometriosis: Micronodular stromal endometriosis and endometriosis with stromal elastosis. Int J Surg Pathol 2000;8:223-227.

32. Clement PB. Pathology of endometriosis. Pathol Annu 1990;25 Pt 1:245-295.

33. Clement PB, Young RH, Scully RE. Necrotic pseudoxanthomatous nodules of ovary and peritoneum in endometriosis. Am J Surg Pathol 1988;12:390-397.

34. Czernobilsky B, Morris WJ. A histologic study of ovarian endometriosis with emphasis on hyperplastic and atypical changes. Obstet Gynecol 1979;53:318-323.

35. Seidman JD. Prognostic importance of hyperplasia and atypia in endometriosis. Int J Gynecol Pathol 1996;15:1-9.

36. Pishvaian AC, Ahlawat SK, Garvin D, Haddad NG. Role of EUS and EUS-guided FNA in the diagnosis of symptomatic rectosigmoid endometriosis. Gastrointest Endosc 2006;63:331-335.

37. Sciume C, Geraci G, Pisello F, Li Volsi F, Facella T, Modica G. [Intestinal endometriosis: An obscure cause of cyclic rectal bleeding]. Ann Ital Chir 2004;75:379-384; discussion 385.

38. Vander Noot MR, III, Eloubeidi MA, Chen VK, et al. Diagnosis of gastrointestinal tract lesions by endoscopic ultrasound-guided fineneedle aspiration biopsy. Cancer 2004;102:157-163. 